AC 2007-990: ACTIVE PROJECT-BASED LEARNING IN STRUCTURAL ANALYSIS: FIELD INSPECTION OF A STEEL TRUSS BRIDGE

Shane Palmquist, Western Kentucky University 


\title{
Active Project-Based Learning in Structural Analysis: Field Inspection of a Steel Truss Bridge
}

\begin{abstract}
The undergraduate civil engineering program at our University offers a project-based curriculum. Students have opportunities to engage in projects that develop their understanding of civil engineering practice. Projects are chosen in support of active student engagement, where the role of students is as learners, observers, assistants and practitioners. For example, in a junior level structural analysis course, students worked in teams to perform a physical field inspection of a steel truss bridge. The physical inspection required students to wear special climbing equipment in order to climb the structure. The top chord members of the trusses and the connections were examined hands-on by the students to located and document areas of deterioration. After completing the inspection, the students were required to analyze the trusses based on the inspection findings.

The focus of this paper is to present the results and work performed by the students as well as how the project was integrated into the course from a pedagogical viewpoint. The project included a hands-on inspection of a steel truss bridge and an analysis of the trusses of the structure based on the inspection results. This approach to active project-based learning offers a unique hands-on experience that engineering students typically appreciate.
\end{abstract}

\section{Introduction}

There is a significant need to expose undergraduate engineering students to real life engineering projects rather than a simulated project that is more hypothetical than practical ${ }^{1}$. Unfortunately, practical projects are too often left to the senior capstone course ${ }^{2}$. However, engineering students upon entering college need exposure to practical projects to better prepare themselves as future engineering practitioners. It is important for engineering students to understand that the study of engineering by nature is both academic and practice based. In the past several decades, greater emphasis has been place on engineering academics ${ }^{3}$.

Practice based projects should be an integral part of engineering courses and should be spread out over all four years of the undergraduate program ${ }^{4}$. For civil engineering students, this means getting students out in the field as much as possible. While lecture and lab based engineering education is important, field experience is equally important. Too often, students lack actual field experience.

Students in an academic setting typically have ample opportunity to become proficient in the pencil and paper rigor of engineering problem solving. However, there is a disconnect between academia and engineering practice ${ }^{5}$. The classroom learning environment is typically a passive experience such as in a lecture hall (with the exception of the laboratory courses), whereas engineering practice is an active experience. Students in a classroom setting need more active 
and engaged experiences ${ }^{6}$. Real life engineering projects, that encourage active participation and physical exposure to real structures such as buildings and bridges, can significantly improve student understanding of the applied principles of engineering analysis and design, and can help bridge the gap between engineering education and practice.

In a junior level structural analysis course, a project was introduced into the curriculum that required field work. The project involved students performing a hands-on inspection and dead load analysis of the trusses of a historical steel bridge.

\section{Background}

College Street Bridge is a four-span, steel, truss structure which crosses the Barren River in Bowling Green, Kentucky (see Figures 1 and 2). Spans 1 through 3 are through trusses, and span 4 is a pony truss. The historic bridge was built in 1915 and presently serves as a pedestrian bridge. The top chord truss members and the vertical truss members of the through trusses are made of built-up riveted steel sections. The lower chord truss members and the diagonal members of the through trusses are steel eyebar members, which connect to steel pins at the joints. The slender tension diagonals are steel bars with a circular cross-section. The members of the pony truss are built-up riveted steel sections.

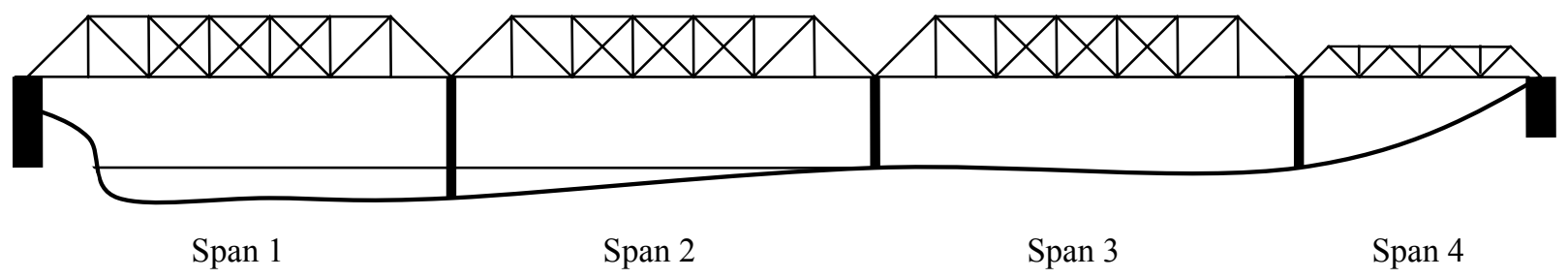

Figure 1: Elevation View of College Street Bridge

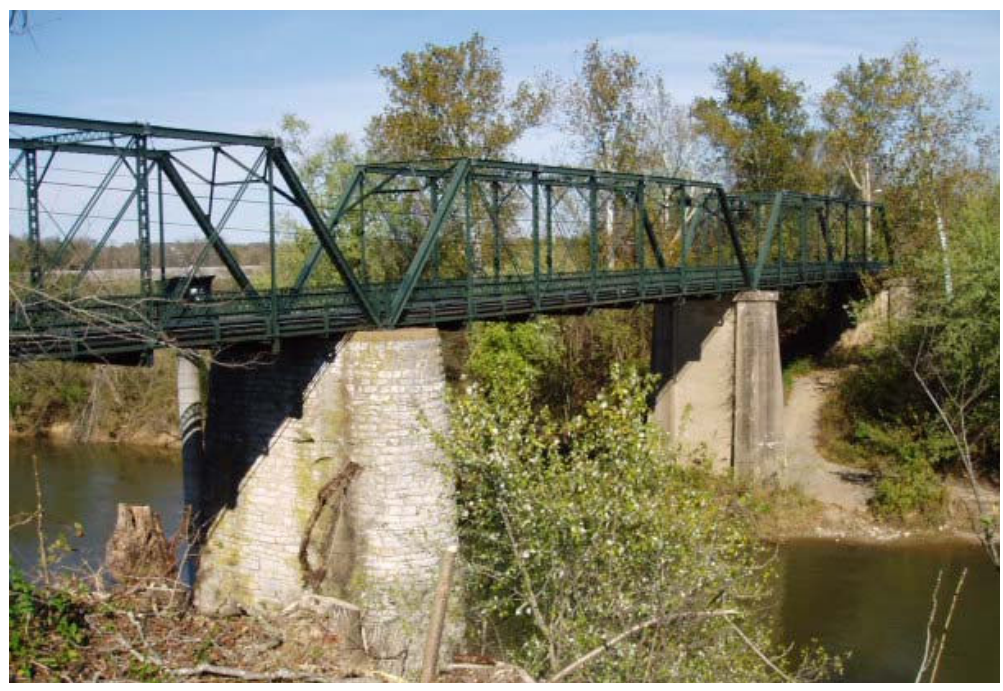

Figure 2: College Street Bridge 
The purpose of the project was to give students an opportunity to work hands-on on a real engineering structure, to see and feel the members and joints of an actual structure. Students were required to perform a structural inspection and dead load analysis of the trusses in spans 1 through 3. The inspection involved three components: basic bridge geometry (since plans of the structure do not exist), member properties, and locating notable areas of deterioration. Basic bridge geometry including length of the truss (lower cord), distance between panel points, lengths of vertical, diagonal and bottom chord members, transverse distance between trusses (centerline to centerline), and roadway width. Member properties included size and shape as well as cross-sectional area. Notable areas of deterioration included section losses and impacted rust.

One of the challenging aspects of this project was the proper integration into the structural analysis curriculum. To accomplish this, the bridge was referred to or used as an example when discussing concepts that could directly relate to the structure. For example, at the beginning of the semester, part of a lecture was used to review the concepts of equilibrium such as finding member forces using the method of sections or the method of joints. The bridge was used to demonstrate this as shown in Figure 3. Thus, over the course of the semester when discussing topics such as: beam theory; shear and moment diagrams of beams and floorbeams; moment area theorems; virtual work method; and Castigliano's theorems, the students became very familiar with the structure.

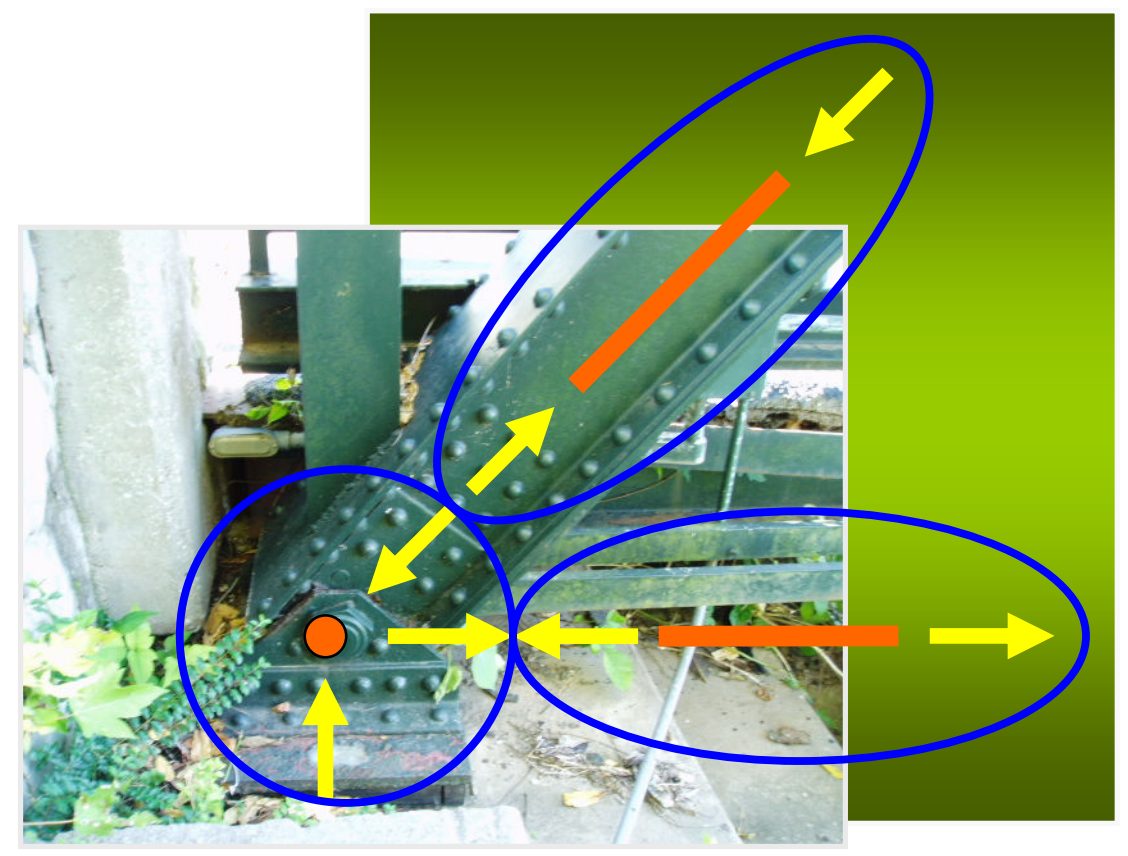

Figure 3. Method of Joints

Assignments and field visits for the project were broken into four major categories. The categories included: an introduction, history, art, and engineering. Each category was further subdivided into components as shown in Table 1. 
Table 1. Project Categories

\begin{tabular}{|l|l|c|c|}
\hline Category & \multicolumn{1}{|c|}{ Components } & Assignments & Field Visits \\
\hline \multirow{3}{*}{ Introduction } & Types of bridges & - & \multirow{2}{*}{2} \\
\cline { 2 - 3 } & Types of truss bridges & 1 & \multirow{2}{*}{2} \\
\cline { 2 - 3 } & Truss bridge components & 1 & \\
\hline \multirow{2}{*}{ History } & Purpose of bridge & - & \multirow{2}{*}{1} \\
\cline { 2 - 3 } & Relevancy to today & 1 & \multirow{2}{*}{1} \\
\hline \multirow{5}{*}{ Ert } & Drawing & - & \\
\cline { 2 - 3 } & Aesthetics & 2 & \multirow{2}{*}{2} \\
& $\begin{array}{l}\text { Existing bridge } \\
\text { documents }\end{array}$ & 1 & \multirow{2}{*}{2} \\
\cline { 2 - 3 } & Inspection preparation & 2 & \\
\cline { 2 - 3 } & Truss inspection & \multicolumn{2}{|c|}{} \\
\cline { 2 - 3 } & Dead load analysis & & \\
\hline
\end{tabular}

\section{Field Work}

A total of six trips to the bridge were required. Students, by themselves, visited the bridge for the first four trips to introduce themselves to the physical structure. It was important that each student recognize that every structure like a person has a unique personality or character. In addition, students need to understand and appreciate the time period that the structure was built in and the relevancy the structure has to the present. The first trip was just to go and see the bridge and become more familiar. The students were then asked to write about there first visit. The second trip required students to go and sketch the cross-sectional shapes of the various members that they saw and identify the type of members, such as a beam, column, bracing member, and so forth. The third visit required students to go and sketch the bridge. For this assignment, the students were to play the role of an artist and sketch the bridge. The sketch was required to be a free-hand sketch, and the students were not allowed to use a straight edge. The fourth visit required students to go to the bridge and read the historical bridge plaque and answer questions. The students for this assignment also had to do a literature search on the structure to answer some of the questions.

To inspect the bridge, new climbing equipment had to be purchased. Five sets of climbing equipment at a cost of $\$ 2,300$ was purchased. Each set included: a chest and waist harness, hardhat with a special chin strap, two lanyards, webbing, carabineers, and gloves. Since the bridge is a pedestrian bridge and part of a community enhancement project for the City of Bowling Green, Kentucky, the city owns the bridge. Students were required to sign release forms for the university and for the city. Due to the real potential danger involved with any inspection involving climbing, three members of the community, who are experienced in bridge climbing and inspection (such as myself), were asked to assist. Each student was paired with either one of these members or me, and each student had the opportunity to climb and traverse one of the trusses on the bridge, as shown in Figures 4-6. 


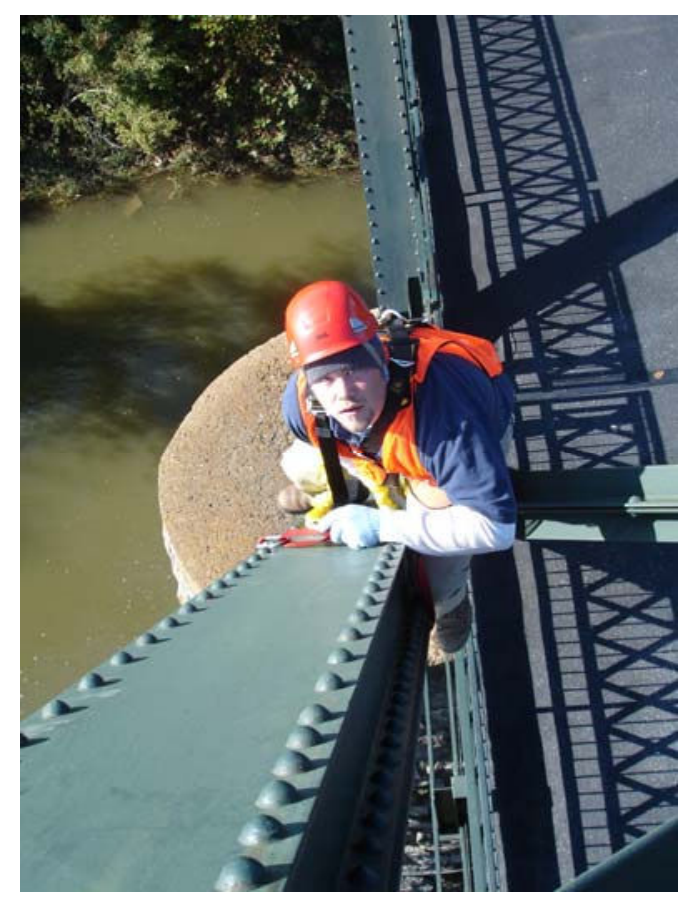

Figure 4. Student Climbing to Top Chord

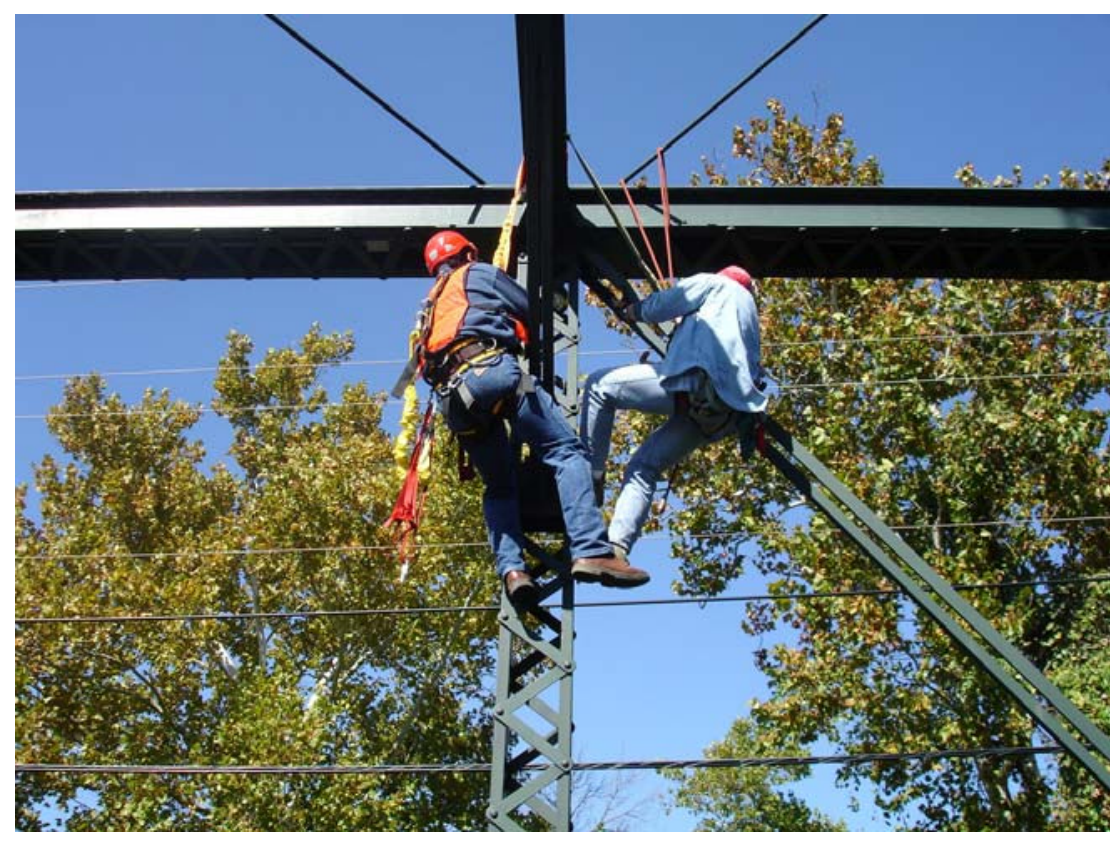

Figure 5. Inspection of a Joint Connection

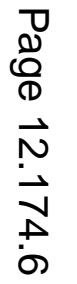




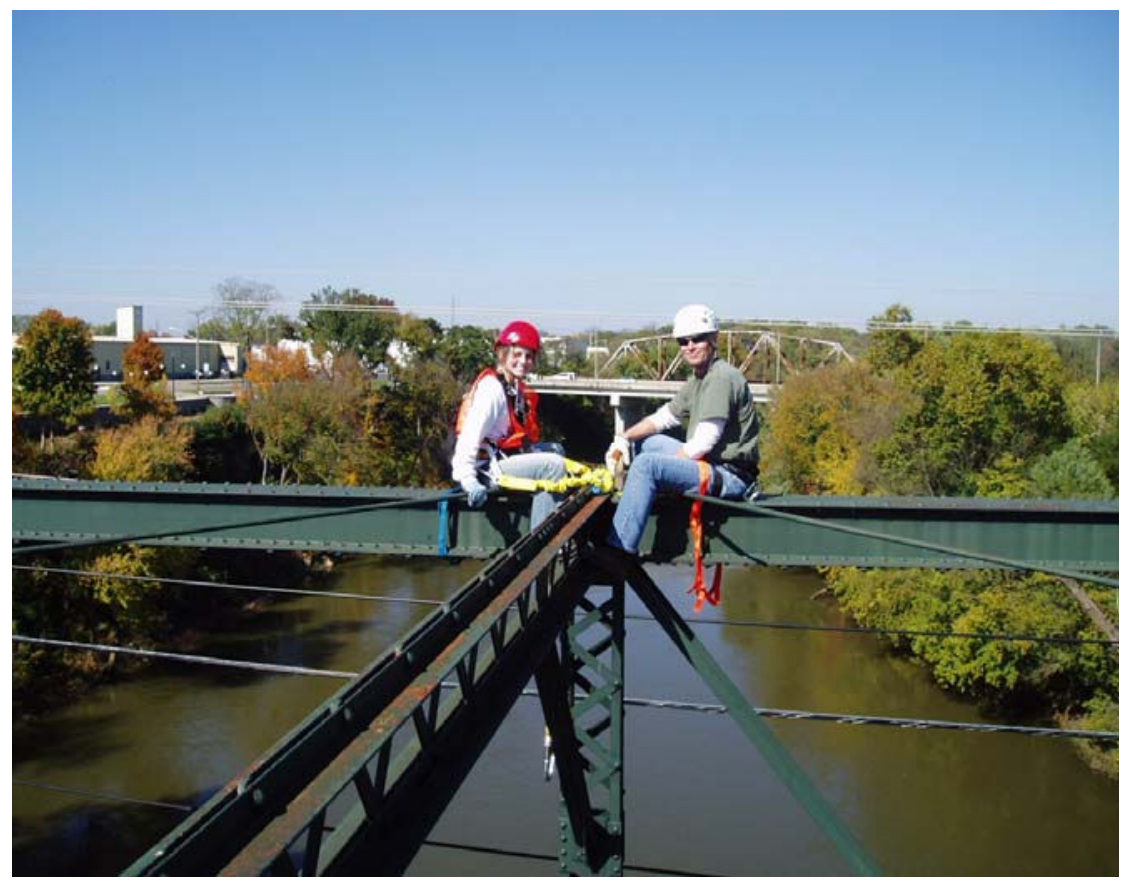

Figure 6. Student and Instructor at a Connection along Top Chord

Of the twelve students in the class, eleven participated and climbed one of the trusses. The class had eleven male students, and one female student. One of the male students could not participate in the truss climb since he was a student athlete away at a competition.

While some of the students were climbing the trusses, the remaining students looked for damage and section loss on the truss members and deck while walking along the top of the deck. Overall the trusses were found to be in good condition especially given the age of the structure. However, a few areas of deterioration were found including the following as shown in Figures 79. 


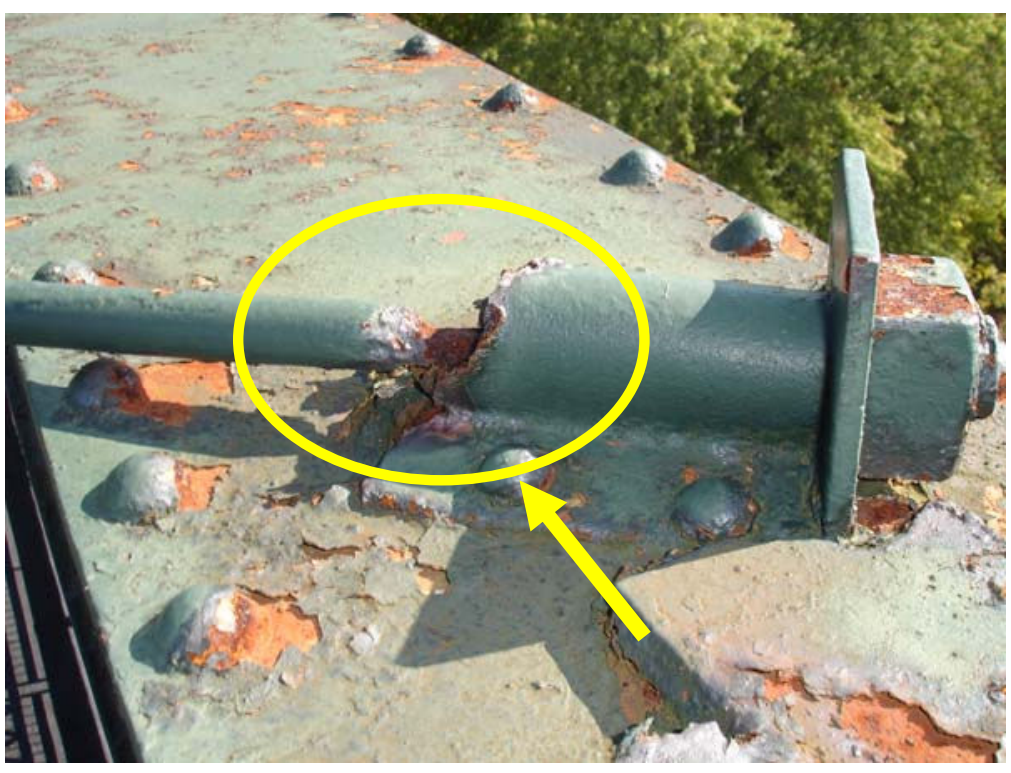

Figure 7. Heavy Section Loss on Upper Lateral Bracing Member, Typical Throughout

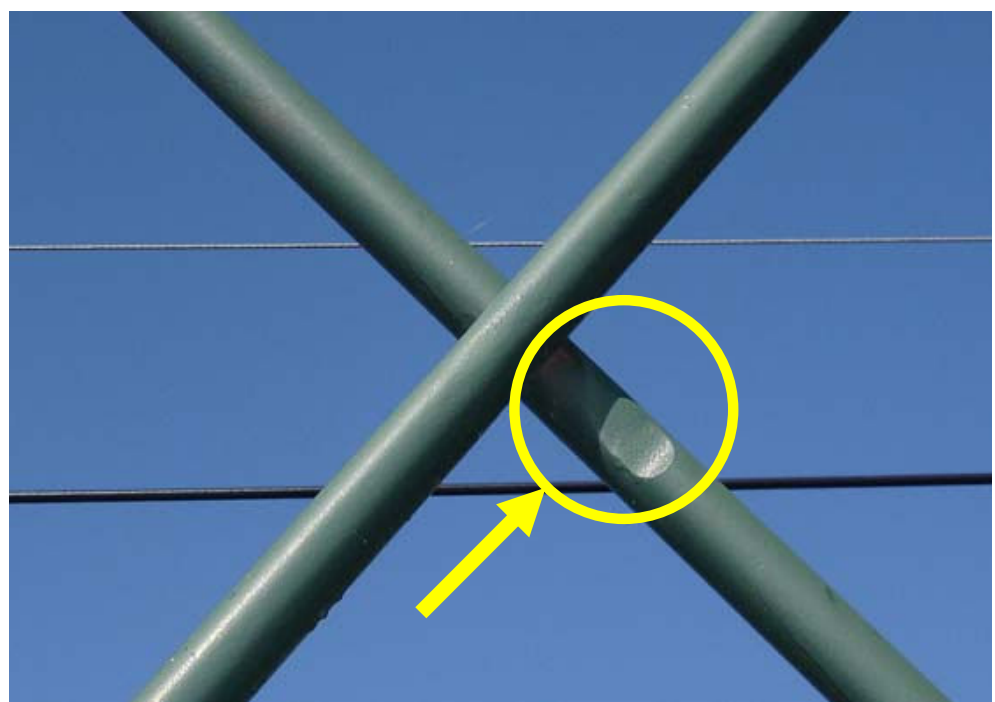

Figure 8. Section Loss on Diagonal Member, Center Bay, West Truss, Span 2. 


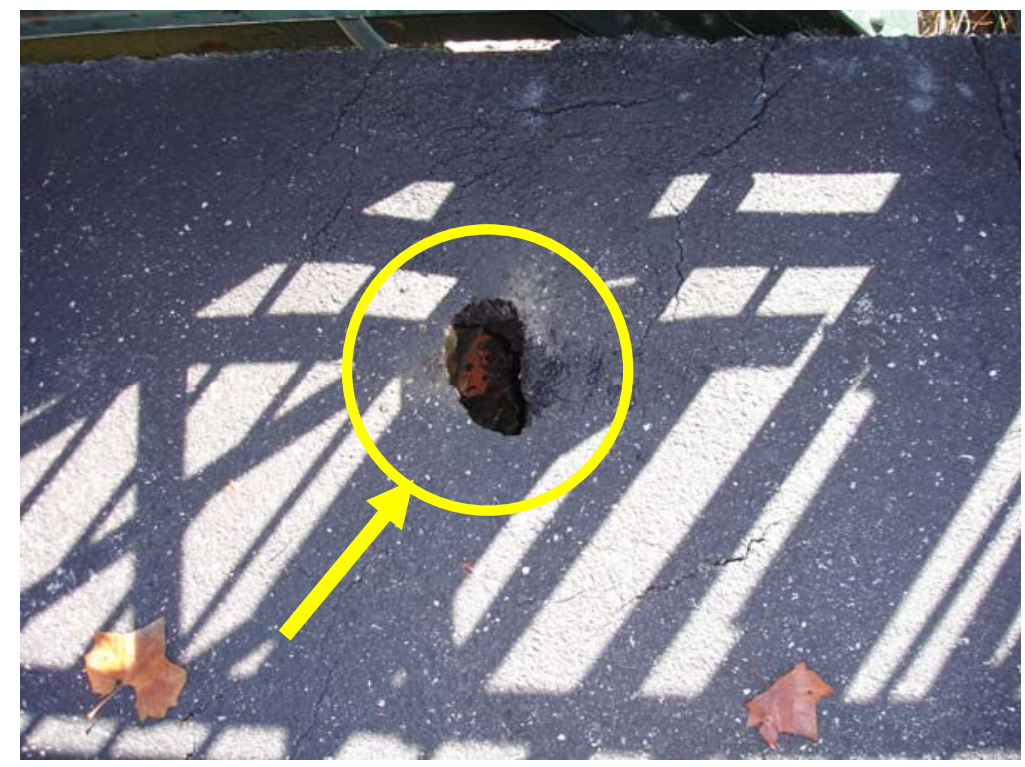

Figure 9. Large Hole in Deck, North End of Span 3 near East Truss.

\section{Results of Student Work}

Truss nomenclature for spans 1 through 3 is shown in Figure 10. From measurements, crosssectional area for each member was calculated and is shown in Table 2 with the respective member length. In the field, minor areas of member deterioration resulting in section losses were found.

Calculating the weight of the truss members and approximating the weight of the floorbeams, stringers, bracing members and deck, the dead loads on the structure were determined and distributed to the respective joint as a joint dead load. Having calculated all of the joint dead loads, the students determined all of the member forces and stresses using a computer software package, VisualAnalysis. The results are shown in Table 2. Note, only the maximum force and corresponding stress for each group of members having the same cross-sectional area are given in Table 2. Select member forces and stresses were checked by hand calculations to verify the results.

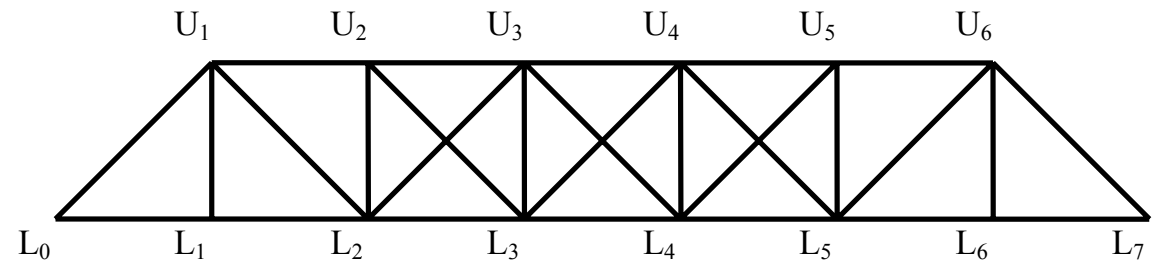

Figure 10. Truss Nomenclature for Spans 1, 2, and 3. 
Table 2: Truss Member Geometry for Spans 1, 2, and 3.

\begin{tabular}{|c|c|c|c|c|c|}
\hline Member $\dagger$ & $\begin{array}{c}\text { Schematic } \\
\text { Cross-Section }\end{array}$ & $\begin{array}{c}\text { Cross-Sectional } \\
\text { Area }\left(\mathrm{mm}^{2}\right)\end{array}$ & $\begin{array}{l}\text { Length } \\
(\mathrm{m})\end{array}$ & $\begin{array}{l}\text { Max Force } t \\
\quad(\mathrm{kN})\end{array}$ & $\begin{array}{c}\text { Max Stress: } \\
\text { (MPa) }\end{array}$ \\
\hline $\begin{array}{l}\mathrm{L}_{0}-\mathrm{U}_{1}, \mathrm{U}_{1}-\mathrm{U}_{2}, \\
\mathrm{U}_{2}-\mathrm{U}_{3}, \mathbf{U}_{3}-\mathbf{U}_{4}, \\
\mathrm{U}_{4}-\mathrm{U}_{5}, \mathrm{U}_{5}-\mathrm{U}_{6}, \\
\mathrm{U}_{6}-\mathrm{L}_{7}\end{array}$ & & 14,050 & $\begin{array}{c}\mathrm{L}_{0}-\mathrm{U}_{1} \\
\mathrm{U}_{6}-\mathrm{L}_{7}=8.00 \\
\text { All others: } \\
5.18\end{array}$ & -233.5 & -16.6 \\
\hline $\begin{array}{l}\mathbf{U}_{2}-\mathbf{L}_{2}, \mathrm{U}_{3}-\mathrm{L} 3, \\
\mathrm{U}_{4}-\mathrm{L}_{4}, \mathbf{U}_{\mathbf{5}}-\mathbf{L}_{\mathbf{5}}\end{array}$ & & 4,330 & 6.10 & -19.8 & -4.5 \\
\hline $\begin{array}{l}\mathbf{U}_{\mathbf{1}}-\mathbf{L}_{\mathbf{2}}, \mathbf{U}_{\mathbf{6}}-\mathbf{L}_{\mathbf{5}}, \\
\mathrm{U}_{2}-\mathrm{L}_{3}, \mathrm{U}_{5}-\mathrm{L}_{4} \\
\mathrm{~L}_{0}-\mathrm{L}_{1}, \mathrm{~L}_{1}-\mathrm{L}_{2} \\
\mathrm{~L}_{5}-\mathrm{L}_{6}, \mathrm{~L}_{6}-\mathrm{L}_{7}\end{array}$ & & 3,900 & $\begin{array}{c}\mathrm{U}_{1}-\mathrm{L}_{2}, \mathrm{U}_{6}-\mathrm{L}_{5} \\
\mathrm{U}_{2}-\mathrm{L}_{3} \\
\mathrm{U}_{5}-\mathrm{L}_{4}=8.00 \\
\text { All others: } \\
5.18\end{array}$ & 113.2 & 29.0 \\
\hline $\begin{array}{l}\mathbf{L}_{2}-\mathbf{L}_{3}, \mathbf{L}_{3}-\mathbf{L}_{4} \\
\mathbf{L}_{4}-\mathbf{L}_{5}\end{array}$ & & 7,780 & 5.18 & 209.7 & 27.0 \\
\hline $\mathrm{U}_{1}-\mathrm{L}_{1}, \mathrm{U}_{6}-\mathrm{L}_{6}$ & & 1,875 & 6.10 & 32.5 & 17.3 \\
\hline $\mathbf{L}_{2}-\mathbf{U}_{3}, \mathbf{L}_{5}-\mathbf{U}_{4}$ & & 805 & 8.00 & 42.5 & 52.8 \\
\hline $\mathbf{L}_{3}-\mathbf{U}_{4}, \mathbf{L}_{4}-\mathbf{U}_{3}$ & & 1,575 & 8.00 & 22.0 & 13.9 \\
\hline
\end{tabular}

$\dagger$ Members bolded had the largest maximum force and stress.

$\$$ A positive value denotes tension, and a negative value denotes compression.

The yield strength of steel is $248 \mathrm{MPa}$. As expected, all trusses had member stresses that were well below the yield strength of the steel.

\section{Summary \& Conclusions}

In a junior level structural analysis course, a project was integrated into the curriculum. The project involved a hands-on structural inspection of the trusses of a historic steel truss bridge. Truss geometry and member properties were measured in the field. Students climbed the trusses of the bridge to locate areas of deterioration and take measurements. The information was used by the students to perform a dead load analysis of the trusses. 
In general, the students really enjoyed the project especially the field work. Through a course integrated project, which involved a significant hands-on experience, students learned to relate structural engineering concepts discussed in class to a real structure.

\section{Acknowledgement}

The author would like to express his sincere gratitude to the Foundation at our University for providing funding for this project. The author would also like to thank the students of structural analysis, CE382 (fall 2006), for their patience and eagerness to learn.

\section{Bibliographic Information}

1. Mahendra, M., "Project-Based Civil Engineering Courses," Journal of Engineering Education, Jan, 1995, pp. $1-5$.

2. Dutson, Alan J., Robert H. Todd, Spencer P. Magleby, Carl D. Sorensen, "A Review of Literature on Teaching Engineering Design Through Project-Oriented Capstone Courses," Journal of Engineering Education, Vol. 86, No. 1, 1997, pp. 17-28.

3. Davis, William J., and Philip D. Strope, "Enhancing Student Learning and Community Service Through Senior Engineering Projects," Annual Conference of the American Society of Engineering Education - Southeast Section, 2000.

4. Craft, Lucille, "Crafting a New Curriculum," ASEE Prism, Jan, 2005, pp. 30-34.

5. Miller, Gregory and Stephen Cooper, "Something Old, Something New: Integrating Engineering Practice into the Teaching of Engineering Mechanics," Journal of Engineering Education, Apr, 1995, pp. 105-115.

6. Shapira, Aviad, "Bringing the Site into the Classroom: A Construction Engineering Laboratory," Journal of Engineering Education, Jan, 1995, pp. 1-5.

7. Tongtoe, Samruam and Siegfried Holzer, "Learning Statics with Multimedia," Annual Conference of the American Society of Engineering Education - Southeast Section, 2001. 